\title{
Reconnaissance of Infrared Emission from the Lunar Nighttime Surface ${ }^{1}$
}

\author{
ROBERT L. WILDEY ${ }^{2}$ \\ Division of Geological Sciences, California Institute of Technology and \\ Mount Wilson and Palomar Observatories \\ Pasadena, California 91109
}

Bruce C. Murray and James A. Westphat

Division of Geological Sciences, California Institute of Technology

Pasadena, California 91109

Introduction. The reconnaissance described in this paper was performed in 1964 and is an extension and refinement of the first observations (1962), in the 8- to 14- $\mu$ wavelength region, of the thermal emission from the lunar nighttime surface [Murray and Wildey, 1964]. The present investigation was intended to sample representatively enough of the lunar surface to determine the general character of the lunar nighttime emission and the relative abundance of nighttime infrared anomalies.

More complete studies of the infrared emission with higher spatial resolution during eclipse were made at about the same time [Saari and Shorthill, 1965].

These two kinds of infrared observations are complimentary since the nighttime emission reflects thermal properties at centimeter depth, in granular material, whereas the eclipse emission is influenced mainly by the uppermost millimeter of such material. Also, the effects of varying albedo can be ignored in the interpretation of the nighttime data.

In the present paper, the observations will be presented with only a minimum of interpretation. Some interpretative questions have been discussed briefly elsewhere [Murray, 1965a, b] or are in preparation [Wildey, 1967]. Comprehensive geophysical analysis of lunar structure requires, however, an integrated interpretation of infrared data in conjunction with polarization data, radar data, radio data, photoelectric

1 Contribution 1442 of the Division of Geological Sciences, California Institute of Technology, Pasadena.

2 Now at Center of Astrogeology, U. S. Geological Survey, Flagstaff, Arizona 86001. photometry and colorimetry, and high-resolution photography such as that being acquired by Lunar Orbiter.

Observational procedure. The 8- to $14-\mu$ photometry was carried out with the 24 -inch telescope and photometer arrangement also used in the investigation reported by Becklin and Westphal [1966], except that the telescope was located at 10,500 feet on White Mountain, near Bishop, California. Observations were collected during parts of the lunations of July and August 1964, but, owing to mechanical problems and weather, only the nights of August 28, 29, and 30 yielded observations of sufficient quality and coverage to permit cataloging of anomalies. Only on August 29 were conditions sufficiently favorable to permit infrared mapping of the nighttime lunar surface. The relevant physical information on the anomalies is summarized in Table 1 . The intensity calibration was obtained by observing Jupiter through an air mass similar to that through which the moon was observed. A peak brightness temperature of $129^{\circ} \mathrm{K}$ has been assumed for Jupiter [Wildey et al., 1965]. It is estimated that maximum systematic errors in the absolute calibration are less than $25 \%$ in specific intensity. The minimum detectable surface brightness corresponds to that of a $100^{\circ} \mathrm{K}$ blackbody above the atmosphere; however, temporal fluctuations in the balance of the two beams of the photometer, usually due to the effects of wind on the telescope tube, introduced perturbations in the zero reference of the scans, in some instances. This effect is, in fact, the principal reason mapping could only be accomplished on a single night.

The diaphragm was $1.22 \mathrm{~mm}$ in diameter, re- 
TABLE 1. Catalog of Lunar Nighttime Anomalies

$I$ is defined as a true thermal surface brightness. It is termed specific intensity in the theory of stellar atmospheres, and elsewhere it is often called luminance. Its absolute units are watts $/ \mathrm{cm}^{2} / \mathrm{steradian} / \Delta \lambda$, and it is directly proportional to the photometer signal in the case of an extended object. The unit of $\Delta I$ used in column four is the thermal brightness of a water-ice blackbody. In column three $\Delta I / I$ is the ratio of the peak brightness (hence signal) excess of an anomaly to the brightness (or signal) of the surrounding region.

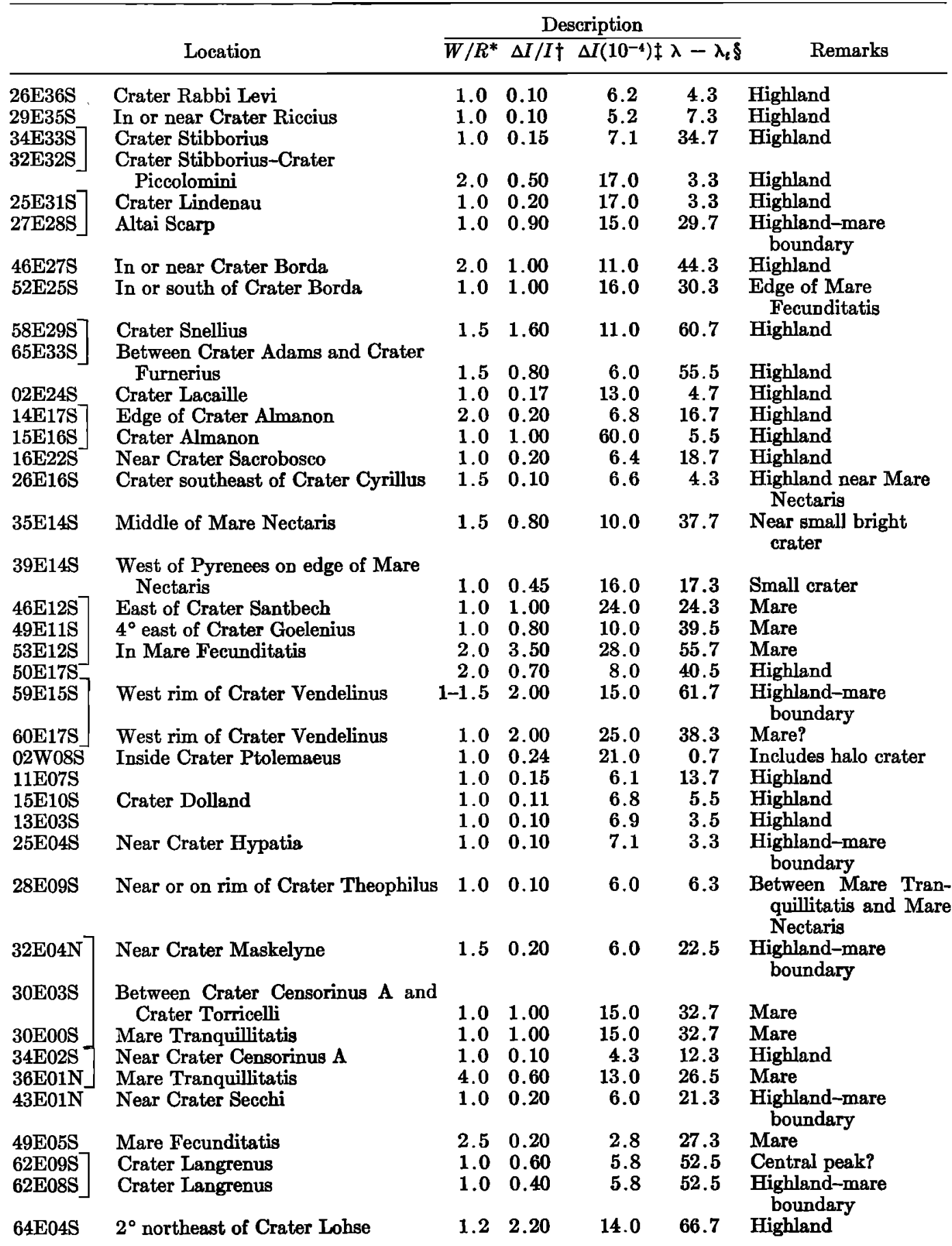


TABLE 1. (Continued)

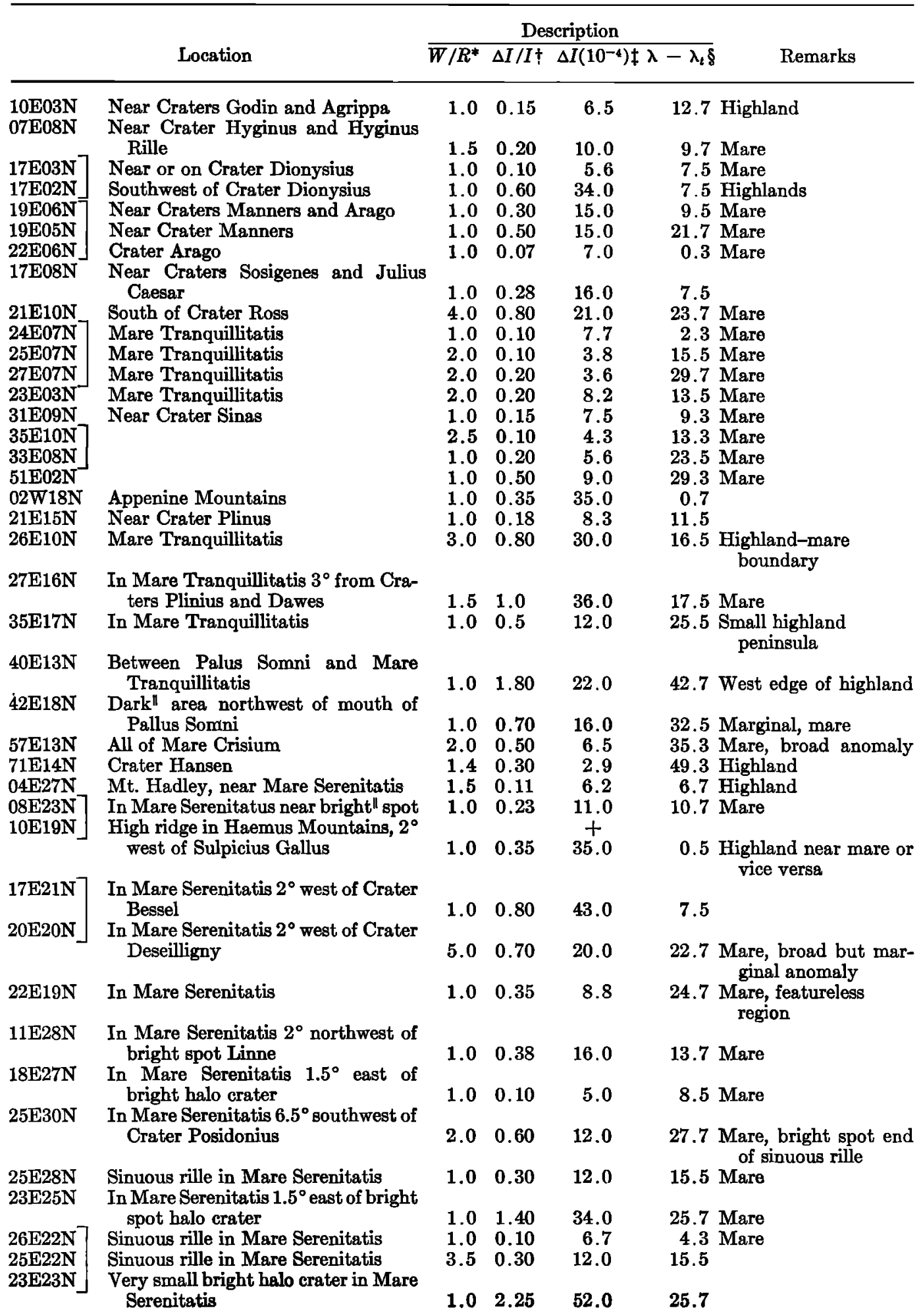


TABLE 1. (Continued)

\begin{tabular}{|c|c|c|c|c|c|c|}
\hline & & & Des & scription & & \\
\hline & Location & $\overline{W / R^{*}}$ & $\Delta I / I \dagger$ & $\Delta I\left(10^{-4}\right)$ & $\overline{\lambda-\lambda_{t} \S}$ & Remarks \\
\hline $29 \mathrm{E} 23 \mathrm{~N}$ & $\begin{array}{l}\text { Crater ray southeast LeMonnier's } \\
\text { archipelago } \\
\text { Upland mountains southeast of Le }\end{array}$ & 1.5 & 0.05 & 2.8 & 7.3 & Mare (Serenitatis) \\
\hline & Monnier & 1.5 & 1.00 & 13.0 & 33.7 & Highland \\
\hline $\begin{array}{l}35 \mathrm{E} 24 \mathrm{~N} \\
44 \mathrm{E} 26 \mathrm{~N}\end{array}$ & In rugged uplands, features indistinct & 1.0 & 0.4 & 17.0 & 13.3 & Highland \\
\hline $\begin{array}{l}44 \mathrm{E} 26 \mathrm{~N} \\
11 \mathrm{E} 34 \mathrm{~N}\end{array}$ & $\begin{array}{l}\text { Dark region in uplands } \\
\text { Tiny bright halo crater in Mare }\end{array}$ & 2.0 & 0.2 & 58 & 22.3 & Hig \\
\hline $18 \mathrm{E} 31 \mathrm{~N}$ & $\begin{array}{l}\text { Serenitatis } \\
\text { In field of small bright halo craters }\end{array}$ & 1.0 & 0.08 & 6.8 & 1.5 & Mare \\
\hline 21E32N & $\begin{array}{l}\text { in Mare Serenitatis } \\
\text { In field of small bright halo craters }\end{array}$ & 1.0 & 0.1 & $\cdots$ & -3.7 & Mare \\
\hline $26 \mathrm{E} 32 \mathrm{~N} 7$ & $\begin{array}{l}\text { in Mare Serenitatis } \\
\text { In Mare Serenitatis }\end{array}$ & $\begin{array}{l}1.0 \\
1.4\end{array}$ & $\begin{array}{l}0.35 \\
0.30\end{array}$ & $\begin{array}{l}35.0 \\
20.0\end{array}$ & $\begin{array}{r}-0.7 \\
4.3\end{array}$ & $\begin{array}{l}\text { Mare } \\
\text { Mare }\end{array}$ \\
\hline 25E36N & In Lacus Somniorum & 1.0 & 0.20 & 7.6 & 15.5 & Mare, not reproduced \\
\hline $\begin{array}{l}\text { 24E33N } \\
28 \mathrm{E} 34 \mathrm{~N}^{-}\end{array}$ & $\begin{array}{l}\text { Crater Luther in Mare Serenitatis } \\
\text { Larger bright halo crater between }\end{array}$ & 1.0 & 0.25 & 6.0 & 26.7 & Mare, marginal case \\
\hline 29E33N & $\begin{array}{l}\text { Luther and Posidonius } \\
\text { Among } 3 \text { bright halo craters in Mare }\end{array}$ & 1.0 & 0.50 & 8.5 & 30.7 & Mare \\
\hline $36 \mathrm{E} 37 \mathrm{~N}\rfloor$ & $\begin{array}{l}\text { Serenitatis } \\
\text { Among bright spots in Lacus Somni- }\end{array}$ & 1.0 & 0.25 & 13.0 & 7.3 & Mare \\
\hline $41 \mathrm{E} 32 \mathrm{~N}$ & $\begin{array}{l}\text { orum } \\
\text { Rugged uplands, rim of Serenitatis }\end{array}$ & 2.0 & 0.15 & 5.5 & 16.5 & Mare \\
\hline 03E45N & & 1.0 & 1.00 & 11.0 & 43.7 & Highland \\
\hline $29 \mathrm{E} 47 \mathrm{~N} 7$ & $\begin{array}{l}\text { Frigorus and Mare Imbrium } \\
1^{\circ} \text { north of large Crater Burg in }\end{array}$ & 1.0 & 1.00 & 60.0 & 5.7 & Highland \\
\hline & Lacus Martis & 1.2 & 0.45 & 25.0 & 7.3 & Mare \\
\hline $\begin{array}{l}28 \mathrm{E} 44 \mathrm{~N}] \\
33 \mathrm{E} 48 \mathrm{~N}\end{array}$ & $\begin{array}{l}\text { Crater Burg } \\
\text { Crater Baily }\end{array}$ & 1.5 & 0.40 & 13.0 & 18.5 & Mare, not reproduced \\
\hline $\left.\begin{array}{l}33 E 48 N \\
38 E 53 N\end{array}\right]$ & $\begin{array}{l}\text { Crater Baily } \\
\text { Upland isthmus between Mare } \\
\text { Frigors and maria-filled Crater }\end{array}$ & 1.0 & 0.25 & 11.0 & 11.3 & Unusual mare \\
\hline & Endymion & 2.0 & 0.50 & 17.0 & 18.5 & Highland \\
\hline $\begin{array}{l}39 \mathrm{E} 49 \mathrm{~N} \\
42 \mathrm{E} 47 \mathrm{~N}\end{array}$ & $3^{\circ}$ north of Crater Hercules & 1.3 & 0.40 & 14.0 & 17.3 & Highland \\
\hline $42 \mathrm{E} 47 \mathrm{~N}$ & Near rim of Crater Atlas & 1.0 & 0.70 & 10.0 & & $\begin{array}{l}\text { Highland, not repro- } \\
\text { duced }\end{array}$ \\
\hline $\begin{array}{l}37 \mathrm{E} 45 \mathrm{~N} \\
10 \mathrm{E} 53 \mathrm{~N}\end{array}$ & $\begin{array}{l}\text { West rim of Hercules } \\
\text { In Mare Frigoris } 1^{\circ} \text { from bright halo }\end{array}$ & 1.2 & 2.80 & 40.0 & 32.7 & Highland \\
\hline $13 \mathrm{E} 54 \mathrm{~N}$ & $\begin{array}{l}\text { crater } \\
\text { In Mare Frigoris }\end{array}$ & $\begin{array}{l}1-2 \\
1.0\end{array}$ & $\begin{array}{l}1.20 \\
0.10\end{array}$ & $\begin{array}{l}52.0 \\
\cdots\end{array}$ & $\begin{array}{r}12.7 \\
-8.3\end{array}$ & $\begin{array}{l}\text { Mare } \\
\text { Mare, tall mountain } \\
\text { peak }\end{array}$ \\
\hline $\begin{array}{l}04 \mathrm{E} 58 \mathrm{~N} \\
22 \mathrm{E} 57 \mathrm{~N}^{-}\end{array}$ & $\begin{array}{l}\text { In Mare Frigoris } 2^{\circ} \text { southwest of } \\
\text { Crater Archytas } \\
\text { In Mare Frigoris } 1^{\circ} \text { north of Crater }\end{array}$ & 1.0 & 0.20 & ‥ & -17.3 & Mare \\
\hline $37 \mathrm{E} 59 \mathrm{~N}$ & $\begin{array}{l}\text { Galle } \\
\text { Uplands east of Mare Frigoris }\end{array}$ & $\begin{array}{l}1.0 \\
2.0\end{array}$ & $\begin{array}{l}0.10 \\
0.30\end{array}$ & $\begin{array}{l}10.0 \\
12.0\end{array}$ & $\begin{array}{r}0.3 \\
15.3\end{array}$ & $\begin{array}{l}\text { Mare } \\
\text { Highland, superposi- } \\
\text { tion confused }\end{array}$ \\
\hline $19 \mathrm{E} 51 \mathrm{~N}$ & East rim of Ari & 2.0 & 0.70 & 35.0 & 9.5 & Mare \\
\hline $27 \mathrm{E} 55 \mathrm{~N}$ & In Mare Frigoris near Crater Galle & 1.6 & 0.50 & 9.0 & 29.7 & $\begin{array}{l}\text { Mare, marginally re- } \\
\text { produced }\end{array}$ \\
\hline $54 \mathrm{E} 51 \mathrm{~N}$ & $\begin{array}{l}\text { In crater chain } 2^{\circ} \text { south of Crater } \\
\text { Endymion }\end{array}$ & 1.0 & 0.35 & 5. & & \\
\hline $53 \mathrm{E} 64 \mathrm{~N}$ & North of Crater Strabo & 1.0 & 2.20 & 17.0 & 55.7 & hland \\
\hline
\end{tabular}

* The apparent width of the anomalous feature expressed as a ratio to the instrumental spatial resolution. $\dagger$ The relative intensity contrast of the anomaly to the surrounding area.

† The peak intensity from the anomaly expressed as a fraction of the brightness from a $273^{\circ} \mathrm{K}$ blackbody. $\$$ The longitude difference between the anomaly and the terminator at the time of the observation. II Visible light. 
sponding to an area $45 \pm 2 \mathrm{~km}$ in diameter at the subearth point of the moon (1/77 of the lunar diameter). Expressed in degrees of lunar latitude at the subearth point, this corresponds to a circle of $0.7^{\circ}$ radius. The spatial resolution of the photometer is estimated to be approximately that defined by the geometric aperture.

The telescope was set to track the moon in declination, and drift curves were made in pairs. Each pair was offset approximately 1.5 arc minute of declination. Multiple photographs of the lunar image reflected from the aperture plate were acquired through the photometer during each scan after passage onto the bright side of the moon. Hence, transcription to an appropriately librated selenographic coordinate projection could be made both directly from the photographs and from ephemeris data and the time of terminator crossing, which was also recorded. Both methods were used and compared; a maximum absolute positional error corresponding to three times the aperture dimension has been estimated on this basis. A more elaborate positioning technique [Wildey, 1964] designed for this work was not used owing to a lack of proper data handling facilities.

Data. Figure 1 is an 8- to $14-\mu$ brightness temperature map of the nighttime surface of the moon acquired on the night of August 29, 1964. The terminator position shown is as it appeared visually and photographically through the photometer. The unexpectedly complex brightness temperature distribution arises from the large number of nighttime thermal anomalies and from irregular enhancements of some maria regions.

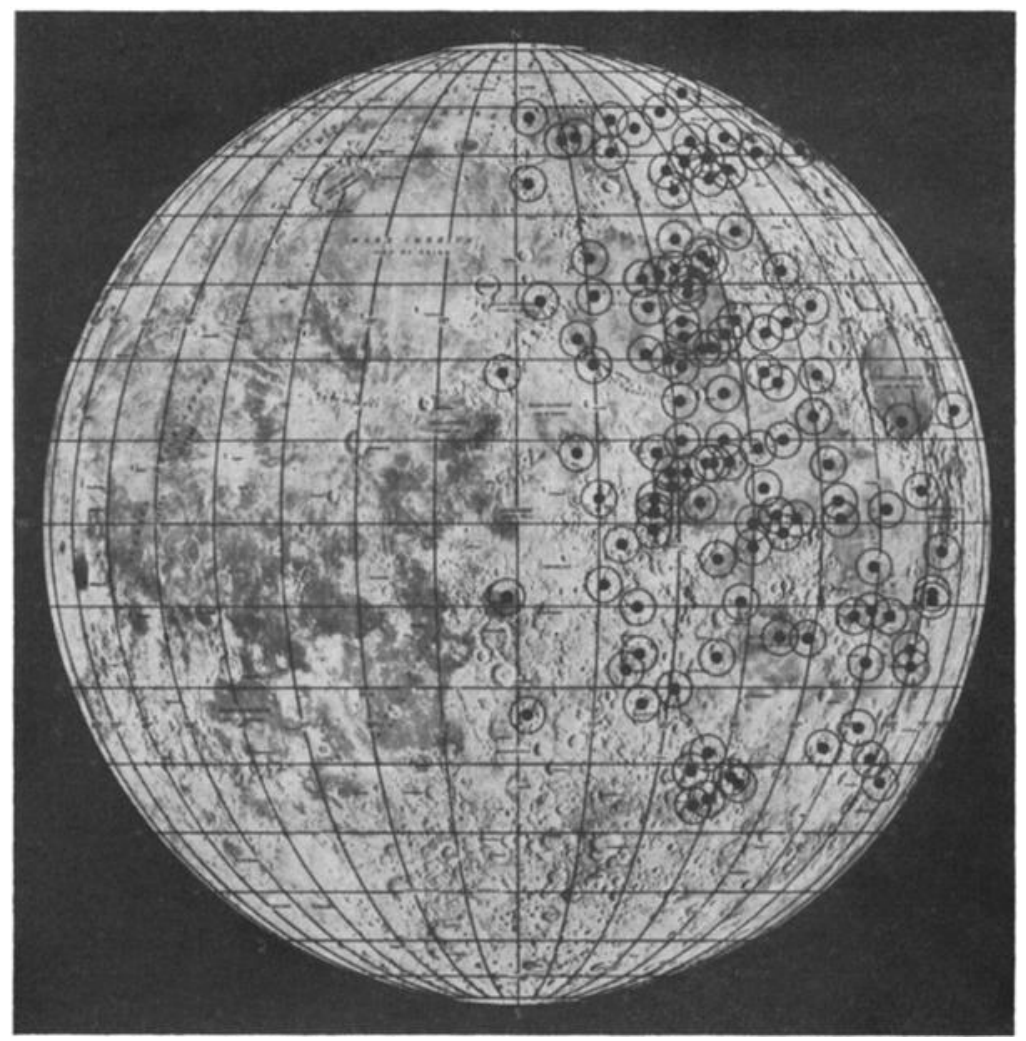

Fig. 1. Location of nighttime infrared anomalies observed on the nights of August 28, 29, and 30, 1964. Filled circles correspond to aperture size and surrounding circles define maximum positional uncertainty. Base map is mosaic compiled by the U. S. Air Force Aeronautical Chart and Information Center, (LEM-1A, 2nd Edition, November 1962). 
Table 1 is a catalog of nearly all anomalous infrared emission features recognizable on the scans of the three nights August 28, 29, and 30. Figure 2 shows the locations of these anomalies on the moon. No areas of anomalously low emission were recognized. Some duplication exists between entries of similar selenographic coordinates acquired on successive nights. Also, true associations of anomalies also exist and individual features occasionally show considerable structure. Associations, duplications, or both are evident from Figure 2 and are indicated by grouped entries in Table 1.

Approximately one-third to three-quarters of the available nighttime surface was sampled on each of the three nights. Noting that the average number of anomalies detected per night is about 35 , and that about $50 \%$ of the moon was shadowed, one would estimate the total number of such anomalies on the visible hemisphere of the moon to be close to 200 .

Interpretation. A most striking feature of Figure 1 is the low level enhanced emission from some maria areas, especially Mare Crisium. Similar but not completely corresponding effects have been observed in the eclipse data [Saari and Shorthill, 1965]. In particular, the enhanced emission of Mare Crisium is peculiar to the lunar nighttime. We have investigated whether a systematic difference in thermal properties of maria and upland regions is indicated by the scans acquired on August 29. This was accomplished by comparing portions of the midlatitude scans that are free from strong anomalies,

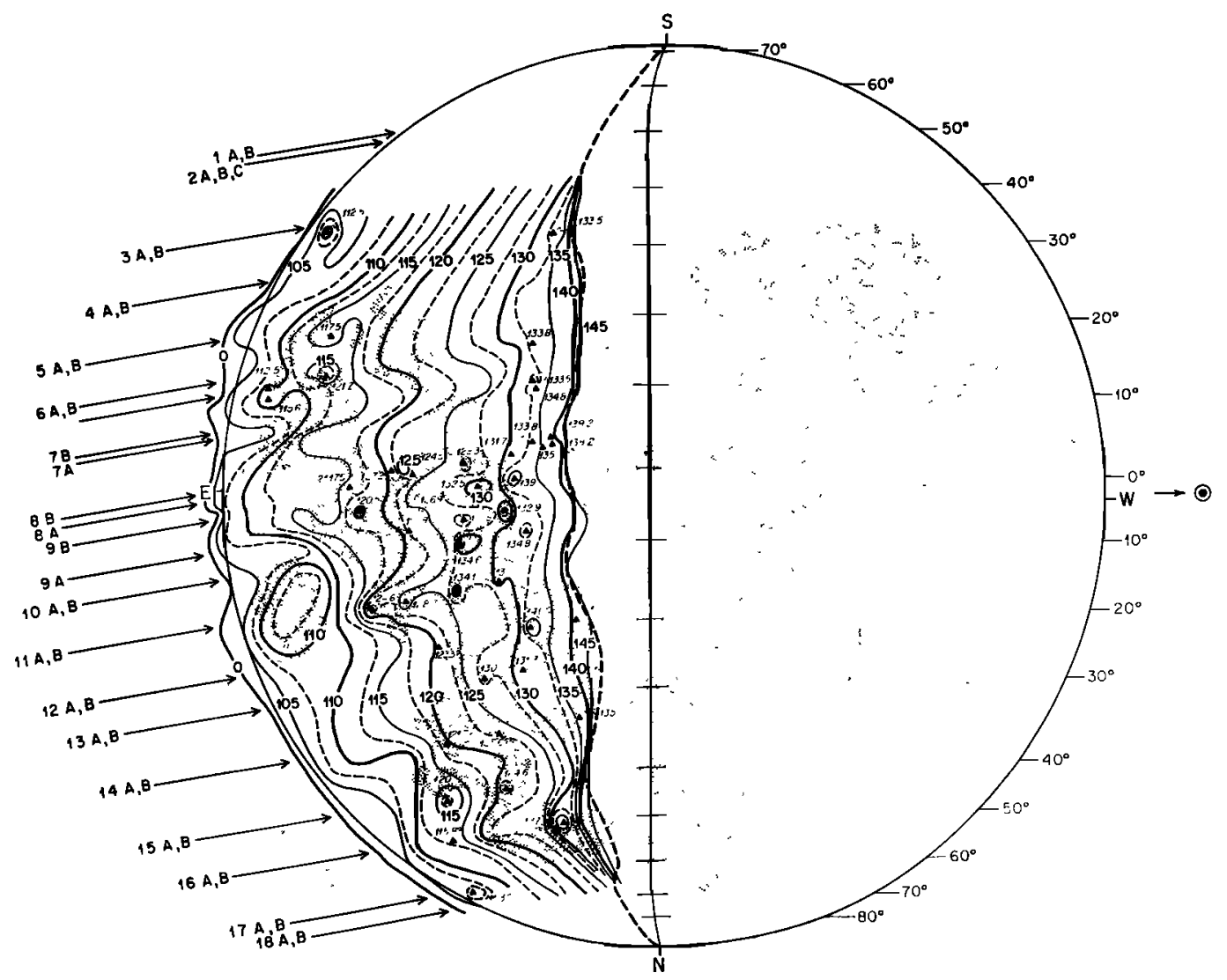

Fig. 2. Brightness temperature (8-14 $\mu$ ) map for third quarter moon of August 29, 1964, 1030 to 1156 hours UT. Terminator tracing is shown as heavy curve. Small triangles are narrow infrared anomalies or hot spots obtained the same night (see Table 1 for those of all nights). Mare regions are shaded. The librated lunar equator and prime meridian are mapped. Arrows at disk edge indicate scan tracks with numbers and letters for retraces. 


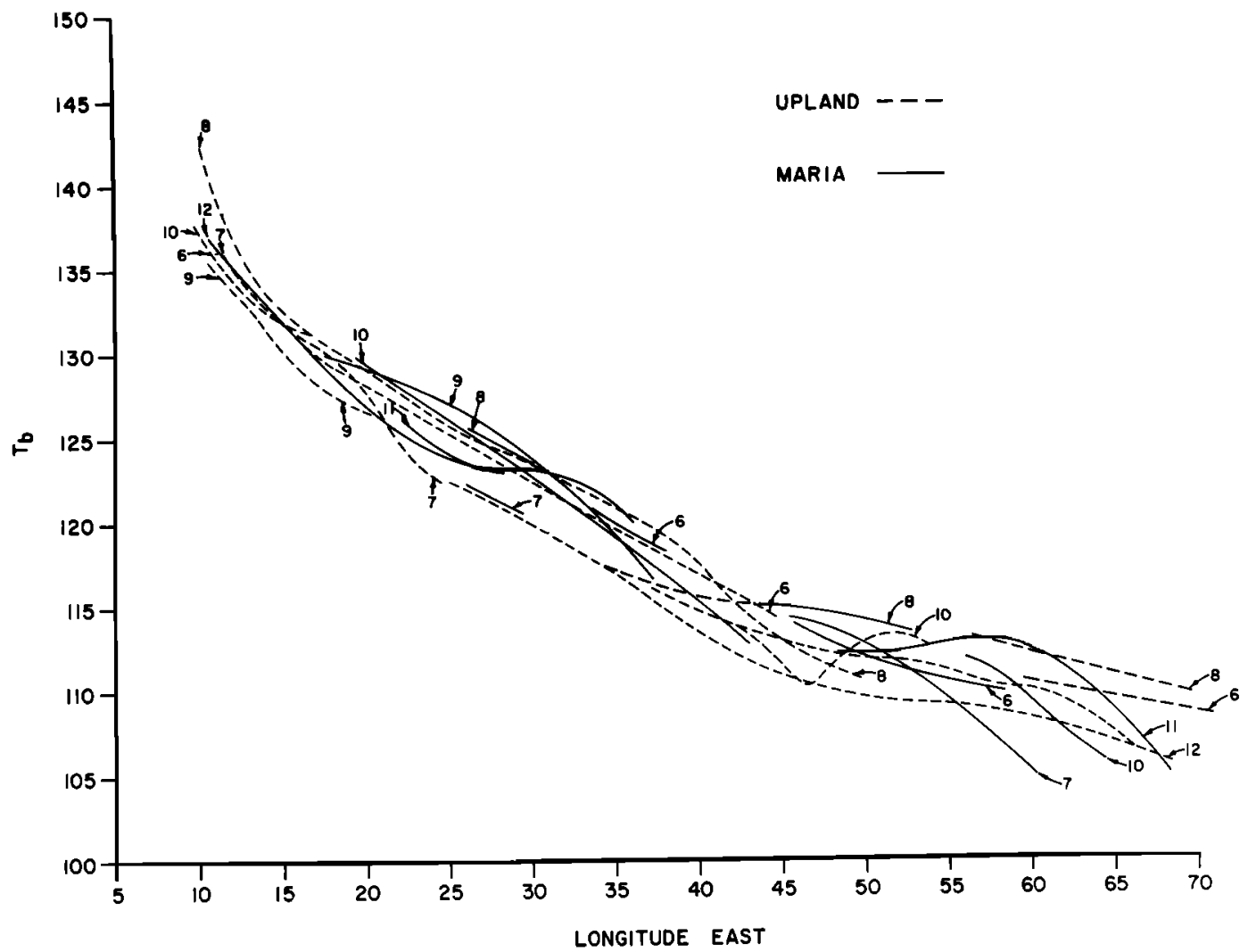

Fig. 3. Brightness temperature versus selenographic longitude for several of the scans of Figure 1. Hence, the normal lunar cooling curve. Note difference curve representation for emission from maria and uplands. Terminator longitude (average) is $9.5^{\circ} \mathrm{E}$.

as shown in Figure 3. It can be seen that any systematic difference is concealed by the intrinsic variability of each region. The scatter of Figure 3 can also be taken to represent the level of precision to which 'the' lunation cooling curve of 'the' moon is meaningful.

Acknowledgment. This research was supported by funds of grant NSG 56-60 from the National Aeronautics and Space Administration.

\section{REFGRENCES}

Becklin, E. E., and J. A. Westphal, Infrared observations of comet 1965f, Astrophys. J., 145, $445-453,1966$.

Murray, B. C., Infrared evidence of differential surface processes on the moon, Symposium on the Physics of the Moon, London, June 1-4, 1965, Royal Society, p. 124, 1965 .

Murray, B. C., Current problems in the interpre- tation of lunar physical observations, Proc. Caltech-JPL Lunar and Planetary Conf., September 18-18, 1965, pp. 32-33, $1965 b$.

Murray, B. C., and R. L. Wildey, Surface temperature variations during the lunar nighttime, Astrophys. J., 199, 734-750, 1964.

Saari, J. M., and R. W. Shorthill, Infrared observations of the lunar eclipse of December, 1964, Nature, 205, 964-965, 1965.

Wildey, R. L., A computer program for the transformation of lunar observations from celestial to selenographic coordinates, Icarus, 3, 136$150,1964$.

Wildey, R. L., The nocturnal heat sources of the surface of the moon, Monthly Notices Roy. Astron. Soc., 128, to be published, 1967.

Wildey, R. L., B. C. Murray, and J. A. Westphal, Thermal infrared emission of the Jovian disk, J. Geophys. Res., 70, 3711-3719, 1965.

(Received February 13, 1967.) 